Article

\title{
Predictability of the Realised Volatility of International Stock Markets Amid Uncertainty Related to Infectious Diseases
}

\author{
Sisa Shiba ${ }^{1} \mathbb{D}$, Juncal Cunado ${ }^{2} \mathbb{D}$ and Rangan Gupta ${ }^{1, * \mathbb{D}}$ \\ 1 Department of Economics, University of Pretoria, Pretoria 0002, South Africa; u20810939@tuks.co.za \\ 2 Department of Economics, University of Navarra, 20280 Pamplona, Spain; jcunado@unav.es \\ * Correspondence: rangan.gupta@up.ac.za
}

check for

updates

Citation: Shiba, Sisa, Juncal Cunado, and Rangan Gupta. 2022.

Predictability of the Realised

Volatility of International Stock

Markets Amid Uncertainty Related to Infectious Diseases. Journal of Risk and Financial Management 15: 18. https://doi.org/10.3390/jrfm15010018

Academic Editor: Thanasis Stengos

Received: 24 November 2021

Accepted: 24 December 2021

Published: 5 January 2022

Publisher's Note: MDPI stays neutral with regard to jurisdictional claims in published maps and institutional affiliations.

Copyright: (C) 2022 by the authors. Licensee MDPI, Basel, Switzerland. This article is an open access article distributed under the terms and conditions of the Creative Commons Attribution (CC BY) license (https:// creativecommons.org/licenses/by/ $4.0 /)$.

\begin{abstract}
In the context of the great turmoil in the financial markets caused by the COVID-19 pandemic, the predictability of daily infectious diseases-related uncertainty (EMVID) for international stock markets volatilities is examined using heterogeneous autoregressive realised variance (HAR$\mathrm{RV}$ ) models. A recursive estimation approach in the short-, medium- and long-run out-of-sample predictability is considered and the main findings show that the EMVID index plays a significant role in forecasting the volatility of international stock markets. Furthermore, the results suggest that the most vulnerable stock markets to EMVID are those in Singapore, Portugal and The Netherlands. The implications of these results for investors and portfolio managers amid high levels of uncertainty resulting from infectious diseases are discussed.
\end{abstract}

Keywords: uncertainty; infectious diseases; COVID-19; international stock markets; realised volatility; forecasting

\section{Introduction}

The coronavirus pandemic has questioned the traditional "safe haven" nature of the international stock markets index (Kopyl and Lee 2016; Gupta et al. 2021; Kinateder et al. 2021; Kizys et al. 2021), casting doubts on whether these markets can be considered attractive for portfolio diversification and hedging benefits in periods of infectious disease episodes.

In fact, the COVID-19 outbreak was followed by remarkable negative responses in stock market returns, as reported in recent academic literature (Al-Awadhi et al. 2020; Harjoto et al. 2021; Lyócsa et al. 2020; Zhang et al. 2021; Gao et al. 2021; Mazur et al. 2021; Ashraf 2021). In that time period, the US benchmark stock markets index, the S\&P 500 declined by approximately $4.9 \%$, the Nasdaq decreased by $4.7 \%$ and the Dow Jones experienced its biggest drop since 1987 (Wang et al. 2020). Furthermore, Lyócsa et al. (2020), for example, showed that the fear of the coronavirus (measured as the google search volume on this topic) is a valuable variable to predict stock price changes around the world. Moreover, Lyócsa and Molnár (2020), Zaremba et al. (2020), Zhang et al. (2020), Gao et al. (2021) and Mazur et al. (2021) allude that all crises, including the COVID-19 pandemic, have one common feature, i.e., extreme market volatility (Zhang and Wei 2010; Kang et al. 2017). Stock market volatility has been a topic of interest in the academic literature, since stock market volatility is a key feature for option pricing, financial market regulation, investment or hedging decisions (Poon and Granger 2003; Chen et al. 2019; Shiba and Gupta 2021), so that many papers attempt to predict stock market volatility. In the framework of this literature, this paper analyzes to what extent the uncertainty related to infectious diseases plays a significant role in forecasting the volatility of a sample of thirty-one international stock markets.

Furthermore, and according to the academic literature, global crises trigger an increase in the connectedness among stock markets. However, the reaction of different stock markets 
to the crisis was not uniform across countries (Ashraf 2021). In this context, Zhang et al. (2021), for example, find volatility spillovers from China to other advanced economies during COVID-19, while they do not find volatility spillovers from those countries to China. On the other hand, the COVID-19 risk spillovers from stock markets in American and European regions increased rapidly but they were minimal for the stock markets in Asia (Liu et al. 2021). Interestingly, Khan et al. (2020) argue that the volatility of the Shanghai Composite Index was minimal due to the drastic and firm measures taken by the Chinese government to contain the spread of the virus, which boosted investor confidence. Zaremba et al. (2021) also find that rapid government policy responses tend to support international stock markets during the pandemic. Furthermore, the government's intervention by restricting commercial activities, introducing the wearing of masks and enforcing social distancing, played a crucial role in containing the spread of COVID-19, and gaining stability again in the market (Baker et al. 2020b). Despite the recent literature on the impact of COVID-19 on financial markets, there is a lack of empirical evidence on the forecasting power of the daily infectious diseases-related uncertainty for international stock market volatility.

In this framework, the objective of this paper is to analyze the predictability of daily infectious diseases-related uncertainty (EMVID) for international stock markets volatilities using the heterogeneous autoregressive realised variance (HAR-RV) model. The key feature of the HAR-RV model is that it uses volatilities from different time resolutions to forecast the realized volatility of equity returns. The model, thereby, captures the main idea motivating the heterogeneous market hypothesis (Müller et al. 1997). This hypothesis stipulates that different classes of market participants populate the stock market, where traders in the different classes differ in their sensitivity to information flows at different time horizons (that is, short-term traders versus long-term traders). For example, traders and speculators are very sensitive to short-term investment horizons, whereas investors are more concerned with long-term investment horizons.

The main contributions of the paper are the following. First, we investigate the ability of uncertainty related to infectious diseases using daily data from January 2000 to June 2021, that is, the analysis includes not only the recent COVID-19 outbreak, but it also includes other infectious diseases such as the H1N1 pandemic in 2009-2010, the Ebola outbreak in 2014-2016, the H5N1, MERS or SARS viruses, etc. As a measure of infectious diseasesrelated uncertainty, we use the newspaper-based index by Baker et al. (2020a). This index tracks the daily equity-market volatility (EMV) in the Chicago Board Options Exchange $(\mathrm{CBOE})$ volatility index. This measure is suitable for a statistical model for predicting the volatility of the international stock markets index. We employ intraday data as it contains information that may lead to more precise and accurate estimates and forecasts. Second, our paper contributes to the literature of the international stock markets index by forecasting its realised volatility computed from $5 \mathrm{~min}$-intervals using the modified version of the heteroscedasticity autoregression (HAR-RV) model by Corsi (2009). More precisely, we extend the benchmark HAR-RV model by adding the daily EMV due to infectious diseases (EMVID) and assess its ability to forecast the international stock markets index RV. Third, we consider out-of-sample short- $(\mathrm{h}=1)$, medium- $(\mathrm{h}=5)$ and long-run $(\mathrm{h}=22)$ predictability of EMVID for international stock market volatility. Finally, the paper studies the predictability of EMVID on the volatilities of 31 international stock market indexes, allowing for international differences on the responses of stock markets to each of the EMVID episodes. This analysis will shed some light on the international portfolio diversification possibilities.

The remainder of the paper is organized as follows. Section 2 presents the data and describes the methodology. Section 3 outlines the empirical results, Section 4 includes a discussion of the main results and Section 5 concludes. 


\section{Data and Methodology}

\subsection{Data}

The data on the international stock market RV are sourced directly from the OxfordMan Institute of Quantitative Finance. We use the Oxford-Man all stock markets index, which is publicly available at: https:/ / realized.oxford-man.ox.ac.uk/data (accessed date: 1 June 2021) These data contain daily close to close non-parametric financial returns $\left(r_{1}, r_{2} \ldots r_{T}\right)$ on international indexes together with their corresponding realised measures $\left(R M_{1}, R M_{2} \ldots R M_{T}\right)$ which are the realised variances. $R M_{t}=\sum x_{j, t}^{2}$, where $x_{j, t}=X_{t_{j, t}}-X_{t_{j-1, t}} . t_{j, t}$ is the time of trade on the $\mathrm{t}$-th day. If the prices are without noise, then as $\min _{j}\left|t_{j, t}-t_{j-1, t}\right| \downarrow 0$, it consistently estimates the quadratic variation of the price process on the t-th day.

Data on the daily infectious diseases-related uncertainty (EMVID) index are developed by Baker et al. (2020a) using a newspaper-based infectious disease equity market volatility tracker from January 1985. The EMVID index is publicly accessible at: http://policyuncertainty.com/infectious_EMV.html (accessed date: 6 June 2021). This index is based on textual analysis of four sets of terms, namely E: economic, economy, financial; M, "stock market", equity, equities, "Standard and Poor"; V: volatility, volatile, uncertain, uncertainty, risky; ID: epidemic, pandemic, virus, flu, diseases, coronavirus, MERS, SARS, Imola, H5N1 and H1N1. In approximately 3000 US newspaper articles, a daily count of at least one term in each of the EMV and ID is attributed in the EMVID index. Contemporary, the counts of all articles on raw EMVID are scaled on the same day. Lately, Baker et al. (2020a) multiplicatively rescale the final series to match the level of the VIX through the overall EMV index and the EMVID index is scaled to total the EMV articles. The range of our data varies according to their earliest data available to the latest possible date from our regressions. Interestingly, our data range covers the disastrous COVID-19 virus and other market events such as the global financial crisis. Note that the EMVID index is the only available measure of uncertainty due to various infectious diseases, including that of the coronavirus. Appendix A, Tables A1 and A2, and Figure A1 present the acronyms of each stock market, the time series plots, and the out-of-sample results of the COVID-19 episode, respectively.

The data plots in Figure A1 depict a constant long-run trend across all the international stock markets index and EMVID during the pre-COVID-19 period, though there are some spikes that quickly return to the mean in the RV series. During the COVID-19 pandemic, we observe a high level of volatility in all the stock markets indexes.

\subsection{Methodology: Heterogeneous Autoregressive Realised Variance (HAR-RV) Model}

To accomplish the primary purpose of this paper, the out-of-sample predictability analysis is conducted using the HAR-RV model by Corsi (2009). In its simplest structure, this model can reproduce important properties contained in financial data, such as long memory, fat tails, self-similarity and multi-scaling behaviour in a satisfactory way (Wang et al. 2019). The benchmark HAR-RV model is

$$
R V_{t+h}=\beta_{0}+\beta_{d} R V_{t}+\beta_{w} R V_{w . t}+\beta_{m} R V_{m . t}+\varepsilon_{t+h}
$$

where $h$ is an index that represents the RV $h$-days ahead. In our case, $h=1,5$ and 22. $R V_{w . t}$ depicts the mean RV from day $t-6$ to day $t-1$, while $R V_{m . t}$ represents the average RV from day $t-22$ to day $t-6$. To capture the interest of our study, we add the EMVID index to the above benchmark HAR-RV model (Equation (1)), obtaining the following extended HAR-RV model:

$$
R V_{t+h}=\beta_{0}+\beta_{d} R V_{t}+\beta_{w} R V_{w . t}+\beta_{m} R V_{m . t}+\theta E M V I D_{t}+\varepsilon_{t+h}
$$




\section{Empirical Results}

In terms of the econometric modelling and predictability, Campbell (2008) and Bouri et al. (2020) argue that an ultimate test for any predictive model is related to its out-ofsample performance. In this paper, our focus is on the out-of-sample predictability of the international stock markets index RV, i.e., we analyze the role of EMVID in forecasting the $\mathrm{RV}$ of the international stock markets index. We consider a recursive estimation approach over the out-of-sample period from the earliest data available in each index to the latest date from our estimation. To obtain the out-of sample multiple structural break test used in the HAR-RV model, we perform the Bai and Perron (2003) test of 1 to M globally determined breaks, and obtain the break dates using the $\mathrm{UD}_{\mathrm{Max}}$ and $\mathrm{WD}_{\mathrm{Max}}$ statistics, and the results are presented in Table 1.

Table 1. Structural breakpoints.

\begin{tabular}{|c|c|c|c|c|c|}
\hline \multirow[b]{2}{*}{ Structural Breakpoints } & \multicolumn{5}{|c|}{ Continent } \\
\hline & Europe & Asia & North America & South America & Australia \\
\hline 2002 & & STI & & & \\
\hline 2003 & $\begin{array}{l}\text { AEX, BFX, FCHI, GDAX1, } \\
\text { IBEX and STOXX50E }\end{array}$ & N225 and SSEC & $\begin{array}{l}\text { DJI, IXIC, MXX, } \\
\text { RUT and SPX }\end{array}$ & & AORD \\
\hline 2004 & FTSE and SSMI & & $\begin{array}{l}\text { BSESN, HIS, KS11 } \\
\text { and NSEI }\end{array}$ & BVSP & \\
\hline 2005 & OSEAX & KSE & GSPTSE & & \\
\hline 2007 & SMSI & & & & \\
\hline 2008 & $\begin{array}{l}\text { OMXC20, OMXHPI and } \\
\text { OMXSPI }\end{array}$ & & & & \\
\hline 2011 & FTMIB & & & & \\
\hline 2014 & BVLG & & & & \\
\hline
\end{tabular}

Note: The structural breakpoints are indicated in each index in their respective continent.

As reported in Table 1, most of the international stock market indexes experienced a structural break in 2003. In fact, market indexes in Europe (AEX, BFX, CHI, GDAX1, IBEX and STOXX59E), Asia (N225 and SSEC) North America (DJI, XIC, MXX, RUT and SPX) and Australia (AROD) were hit by a break in 2003. Several stock market indexes in Europe (FTSE and SSMI), North America (BSESN, HIS, KS11 and NSE) and South America (BVSP) suffered a break in 2004. In 2005, the structural breakpoints are evident in the European OSEAX, Asian KSE and North American GSPTSE market indexes. It is worth mentioning that structural breaks in 2007, 2008, 2011 and 2014 were only found in stock market indexes in Europe (SMSI, OMXC20, OMXHPI, OMXSPI, FTMIB and BVLG). On the contrary, the Asian STI market index suffered a structural break in 2002. The energy crisis in the early 2000s and the global financial crisis may explain the 2003 as well as the 2008 structural breaks in these indexes (Boubaker et al. 2020).

Given these breakpoints, and as we compute the root mean squared forecast errors (RMSFEs) for both the benchmark and extended HAR-RV model for $h=1,5$ and 22, our recursive estimation starts from the earliest date observed breakpoint for each of the indexes. To compute the forecast accuracy for the two latter models, the MSE-F test by McCracken (2007) is employed. Table 2 presents the out-of-sample RMSFEs for the benchmark and for the extended HAR-RV models. Since our primary purpose is to forecast, lower values of the RMSFEs in the out-of-sample models will indicate a better performing model. In order to compute the out-of-sample forecasting gains (FG), the following formula is used:

$$
F G=\left(\frac{R M S F E_{0}}{R M S F E_{1}}-1\right) * 100
$$


The RMSFEs, RMSFE $E_{0}$ and $R M S F E_{1}$ are for the benchmark and extended HARRV models, respectively. Given Equation (3), positive or negative values of FG indicate the gains or losses in percentage. Out-of-sample results (Table 2) indicate that the STI (Singapore) has the highest FG of $0.36 \%$ in the $\mathrm{h}=1$ time horizon followed by an FG of $0.31 \%$ in the $\mathrm{h}=1$ time horizon for BVLG (Portugal), then an FG of $0.27 \%$ in $\mathrm{h}=5$ for STI and AORD, Australia ( $h=1$ and 5 ). This implies that considering the information context of the daily newspaper-based index uncertainty related to infectious diseases in terms of the forecast accuracy of the RMSFEs metrics, the highest FG of $0.36 \%$ is obtained in $h=1$ for STI, with the second-highest FG of $0.31 \%$ on the $h=1$ time horizon for BVLG, then an FG of $0.27 \%$ for STI $(h=5)$ and AORD ( $h=1$ and 5$)$.

Table 2. Out-of-sample forecasting gains.

\begin{tabular}{|c|c|c|c|c|c|c|}
\hline Horizon & RMSE0 & RMSEE 1 & FGs & RMSE0 & RMSEE 1 & FGs \\
\hline \multicolumn{7}{|c|}{ Europe } \\
\hline & \multicolumn{3}{|c|}{ Panel 1: AEX. 8/05/2003 } & \multicolumn{3}{|c|}{ Panel 2: BFX. 7/04/2003 } \\
\hline 1 & 1.3045 & 1.3038 & $0.0571^{* * *}$ & 1.1004 & 1.0985 & $0.1751^{* * *}$ \\
\hline 5 & 0.3400 & 0.3398 & 0.0412 & 0.2957 & 0.2955 & $0.0805^{* * *}$ \\
\hline \multirow[t]{2}{*}{22} & 0.0886 & 0.0886 & 0.0406 & 0.0741 & 0.0741 & 0.0108 \\
\hline & \multicolumn{3}{|c|}{ Panel 3: BVLG. 5/23/2014 } & \multicolumn{3}{|c|}{ Panel 4: FCHI. 8/05/2003 } \\
\hline 1 & 0.5028 & 0.5012 & $0.3110^{* * *}$ & 1.5860 & 1.5852 & $0.0510 * * *$ \\
\hline 5 & 0.1272 & 0.1270 & $0.1456^{* * *}$ & 0.4106 & 0.4105 & 0.0244 \\
\hline \multirow[t]{2}{*}{22} & 0.0363 & 0.0363 & 0.1020 & 0.1049 & 0.1049 & 0.0124 \\
\hline & \multicolumn{3}{|c|}{ Panel 5: FTMIB. 9/07/2011 } & \multicolumn{3}{|c|}{ Panel 6: FTSE. 6/16/2004 } \\
\hline 1 & 1.0066 & 1.0061 & 0.0562 & 2.3748 & 2.3740 & 0.0337 \\
\hline 5 & 0.2611 & 0.2611 & 0.0069 & 0.6379 & 0.6376 & $0.0453^{* * *}$ \\
\hline \multirow[t]{2}{*}{22} & 1.5762 & 1.5746 & $0.1050^{* * *}$ & 0.1544 & 0.1544 & 0.0071 \\
\hline & \multicolumn{3}{|c|}{ Panel 7: GDAX1. 11/27/2003 } & \multicolumn{3}{|c|}{ Panel 8: IBEX. 5/14/2003 } \\
\hline 1 & 1.6491 & 1.6488 & 0.0169 & 1.6762 & 1.6756 & 0.0367 \\
\hline 5 & 0.4298 & 0.4297 & 0.0014 & 0.4403 & 0.4403 & 0.0191 \\
\hline \multirow[t]{2}{*}{22} & 0.1123 & 0.1122 & 0.0134 & 0.1129 & 0.1128 & 0.0346 \\
\hline & \multicolumn{3}{|c|}{ Panel 9: OMXC20. 10/15/2008 } & \multicolumn{3}{|c|}{ Panel 10: OMXHPI. 10/17/2008 } \\
\hline 1 & 2.9683 & 2.9674 & 0.0291 & 4.2473 & 4.2464 & 0.0214 \\
\hline 5 & 0.8047 & 0.8046 & 0.0211 & 1.1248 & 1.1246 & 0.0179 \\
\hline \multirow[t]{2}{*}{22} & 0.2017 & 0.2016 & 0.0198 & 0.2787 & 0.2787 & 0.0165 \\
\hline & \multicolumn{3}{|c|}{ Panel 11: OMXSPI. 10/02/2008 } & \multicolumn{3}{|c|}{ Panel 12: OSEAX. 10/06/2005 } \\
\hline 1 & 2.5614 & 2.5610 & 0.0158 & 3.7652 & 3.7651 & 0.0007 \\
\hline 5 & 0.5640 & 0.5640 & 0.0080 & 0.9853 & 0.9853 & 0.0036 \\
\hline \multirow[t]{2}{*}{22} & 0.1646 & 0.1646 & 0.0158 & 0.2398 & 0.2398 & 0.0142 \\
\hline & \multicolumn{3}{|c|}{ Panel 13: SMSI. 12/17/2007 } & \multicolumn{3}{|c|}{ Panel 14: SSMI. 3/29/2004 } \\
\hline 1 & 2.1409 & 2.1398 & 0.0491 & 1.4816 & 1.4812 & 0.0238 \\
\hline 5 & 0.5566 & 0.5564 & 0.0259 & 0.3832 & 0.3830 & 0.0368 \\
\hline 22 & 0.1392 & 0.1391 & 0.0374 & 0.0988 & 0.0988 & 0.0051 \\
\hline \multicolumn{7}{|c|}{ Panel 15: STOXX50E. 8/07/2003 } \\
\hline 1 & 2.4806 & 2.4795 & $0.0454^{* * *}$ & & & \\
\hline 5 & 0.6680 & 0.6677 & 0.0368 & & & \\
\hline 22 & 0.1606 & 0.1606 & 0.0062 & & & \\
\hline
\end{tabular}


Table 2. Cont.

\begin{tabular}{|c|c|c|c|c|c|c|}
\hline Horizon & RMSE0 & RMSEE 1 & FGs & RMSE0 & RMSEE 1 & FGs \\
\hline \multicolumn{7}{|c|}{ Asia } \\
\hline & \multicolumn{3}{|c|}{ Panel 16: BSESN. 6/16/2004 } & \multicolumn{3}{|c|}{ Panel 17: HIS. 11/09/2004 } \\
\hline 1 & 2.8070 & 2.8047 & $0.0822^{* * *}$ & 1.2294 & 1.2294 & 0.0009 \\
\hline 5 & 0.7339 & 0.7334 & $0.0608^{* * *}$ & 0.3281 & 0.3281 & 0.0003 \\
\hline \multirow[t]{2}{*}{22} & 0.2083 & 0.2082 & 0.0404 & 0.0793 & 0.0793 & 0.0025 \\
\hline & \multicolumn{3}{|c|}{ Panel 18: KS11. 6/16/2004 } & \multicolumn{3}{|c|}{ Panel 19: KSE. 4/01/2005 } \\
\hline 1 & 1.2386 & 1.2384 & 0.0161 & 1.2807 & 1.2801 & $0.0478^{* * *}$ \\
\hline 5 & 0.3273 & 0.3273 & 0.0095 & 0.3395 & 0.3393 & $0.0601 * * *$ \\
\hline \multirow[t]{2}{*}{22} & 0.0860 & 0.0860 & 0.0058 & 0.0840 & 0.0840 & 0.0012 \\
\hline & \multicolumn{3}{|c|}{ Panel 20: N225. 6/06/2003 } & \multicolumn{3}{|c|}{ Panel 21: NSEI. 5/18/2004 } \\
\hline 1 & 1.3336 & 1.3332 & 0.0304 & 3.5197 & 3.5167 & $0.0865^{* * *}$ \\
\hline 5 & 0.3479 & 0.3479 & 0.0089 & 0.9980 & 0.9974 & 0.0552 \\
\hline \multirow[t]{2}{*}{22} & 0.0897 & 0.0897 & 0.0111 & 0.2498 & 0.2497 & 0.0401 \\
\hline & \multicolumn{3}{|c|}{ Panel 22: SSEC. 11/18/2003 } & \multicolumn{3}{|c|}{ Panel 23: STI. 2/28/2002 } \\
\hline 1 & 1.9674 & 1.9673 & 0.0066 & 0.3886 & 0.3872 & $0.3634^{* * *}$ \\
\hline 5 & 0.5201 & 0.5200 & 0.0060 & 0.1032 & 0.1029 & $0.2681^{* * *}$ \\
\hline \multirow[t]{3}{*}{22} & 0.1350 & 0.1350 & 0.0000 & 0.0253 & 0.0253 & $0.0830 * * *$ \\
\hline & \multicolumn{5}{|c|}{ North America } & \\
\hline & \multicolumn{3}{|c|}{ Panel 24: DJI. 5/23/2003 } & \multicolumn{3}{|c|}{ Panel 25: GSPTSE. 11/25/2005 } \\
\hline 1 & 2.0634 & 2.0629 & 0.0220 & 4.9173 & 4.9166 & 0.0131 \\
\hline 5 & 0.5358 & 0.5357 & 0.0088 & 1.2551 & 1.2550 & 0.0053 \\
\hline \multirow[t]{2}{*}{22} & 0.1372 & 0.1372 & 0.0146 & 0.3107 & 0.3107 & 0.0077 \\
\hline & \multicolumn{3}{|c|}{ Panel 26: IXIC. 4/30/2003 } & \multicolumn{3}{|c|}{ Panel 27: MXX. 4/30/2003 } \\
\hline 1 & 1.3706 & 1.3699 & $0.0496^{* * *}$ & 1.4505 & 1.4502 & 0.0177 \\
\hline 5 & 0.3524 & 0.3523 & 0.0304 & 0.3870 & 0.3870 & 0.0116 \\
\hline \multirow[t]{2}{*}{22} & 0.0601 & 0.0601 & 0.0000 & 0.0930 & 0.0930 & 0.0075 \\
\hline & \multicolumn{3}{|c|}{ Panel 28: RUT. 4/29/2003 } & \multicolumn{3}{|c|}{ Panel 29: SPX. 4/25/2003 } \\
\hline 1 & 1.2246 & 1.2232 & $0.1099^{* * *}$ & 1.8266 & 1.8264 & 0.0097 \\
\hline 5 & 0.3199 & 0.3196 & $0.0798^{* * *}$ & 0.4807 & 0.4807 & 0.0046 \\
\hline \multirow[t]{3}{*}{22} & 0.0833 & 0.0833 & 0.0012 & 0.1217 & 0.1217 & 0.0132 \\
\hline & & $\begin{array}{c}\text { South } \\
\text { America }\end{array}$ & & & Australia & \\
\hline & \multicolumn{3}{|c|}{ Panel 30: BVSP. 10/21/2004 } & \multicolumn{3}{|c|}{ Panel 31: AORD. 5/02/2003 } \\
\hline 1 & 1.8477 & 1.8470 & 0.0405 & 1.0930 & 1.0900 & $0.2710^{* * *}$ \\
\hline 5 & 0.4764 & 0.4763 & 0.0227 & 0.2706 & 0.2698 & $0.2791 * * *$ \\
\hline 22 & 0.1270 & 0.1270 & 0.0394 & 0.0724 & 0.0724 & 0.0069 \\
\hline
\end{tabular}

Note: The forecasting gains. $F G=\left(\frac{R M S F E_{0}}{R M S F E_{1}}-1\right) * 100$. where $R M S F E_{0}$ and $R M S F E_{1}$ are root mean squared forecast errors (RMSFE $E_{s}$ ) of the benchmark HAR-RV model (Equation (1)) $R V_{t+h}=\beta_{0}+\beta_{d} R V_{t}+\beta_{w} R V_{w . t}+$ $\beta_{m} R V_{m . t}+\varepsilon_{t+h}$ and $R V_{t+h}=\beta_{0}+\beta_{d} R V_{t}+\beta_{w} R V_{w . t}+\beta_{m} R V_{m . t}+\theta E M V I D_{t}+\varepsilon_{t+h}$ the extended HAR-RV model (Equation (2)). RV is the daily realised volatility estimation of the international stock market index; EMVID is the newspaper-based uncertainty index due to infectious diseases. ${ }^{* * *}$ presents the significance of the MSF-F test statistics at the $1 \%$ level.

Comparing our findings for all the stock market indexes under analysis, moderate FGs, ranging from $0.03 \%$ to $0.10 \%$, (in particular for the $\mathrm{h}=1$ and 5 horizons) are observed in the AEX, BSESN, BVSP, FCHI, FTMIB, FTSE, IXIC, KSE, NSEI, SMSI and STOXXSOE (in no particular order). Furthermore, our findings indicate that across all time horizons for HSI, $\mathrm{h}=5$ for GDAX1, $\mathrm{h}=22$ for IXIC, KSE and RUT, $\mathrm{h}=1$ and 5 for OSEAX and SPX, there is no forecast gain or loss. This indicates that in the lowest bound, we cannot infer any gain or loss in the latter international stock market indexes. Given these results, it is 
evident that the extended model, Equation (2), out-performs the basic model Equation (1). According to the MSE-F statistics ${ }^{1}$, these results are significant for $\mathrm{h}=1,5$ and 22 for STI and $h=1$ and 5 for AORD, BFX, BSESN, BVLG, KSE and RUT. We observe the same results for $\mathrm{h}=1$ for AEX, FCHI, IXIC. NSEI and STOXX50E, for $\mathrm{h}=2$ in FTSE and $\mathrm{h}=3$ for FTMIB. ${ }^{2}$ The above results imply that uncertainty associated with infectious diseases has important information for predicting the future path of international stock markets' index RV in the short-, medium- and long-run.

Finally, we assess the forecasting power of the EMVID during the COVID-19 outbreak. With this purpose, our out-of-sample period covers the data from January 2020, and the in-sample period includes the same number of observations starting in 2018 to December 2019 , i.e., we make the in- and out-of-sample periods of equal size. The period of the latter analysis incorporates all the phases of COVID-19, the first, second and the third wave $^{3}$. Having exclusively conducted our analysis based on the COVID-19 episode, the out-of-sample results indicate that the highest FG of $0.93 \%$ is for KSE $(h=1)$, Pakistan, followed by $0.91 \%$ for BVLG $(h=22)$, Portugal. That is, considering the information context of the daily newspaper-based index uncertainty related to infectious diseases based on the forecast accuracy of the RMSFE metrics during the COVID-19 episode, we can obtain the highest FG of $0.93 \%$ in the $h=1$ model for KSE and $0.91 \%$ in the $h=22$ model for BVLG. Our results also indicate an FG of $0.01 \%$ for AORD $(\mathrm{h}=22)$ followed by a $0.02 \%$ for STI $(h=22)$. In contrast, for MXX, N225, OSEAX and SSEC, across all time horizons, there is a forecasting loss, with the highest loss of $3.22 \%$ followed by $3.04 \%$ for OSEAX and NSEI in the $\mathrm{h}=1$ time horizon, respectively. The least forecast loss of $0.01 \%$ is evident in $\mathrm{h}=1$ for OMXC20. This implies that we can obtain the least forecasting loss of $0.01 \%$ in $\mathrm{h}=1$ for OMXC20. These results are significant at a $10 \%$ level of significance ${ }^{4}$. The KSE in Pakistan, KS11 in South Korea and STI in Singapore appear to be the most volatile stock market indexes during the COVID-19 period followed by the AORD in Sydney, Australia (Table A2). ${ }^{5}$

Concerning our findings, this paper contributes to the existing literature showing that daily infectious diseases-related uncertainty or uncertainty related to pandemics and epidemics have the power to forecast international stock markets index RV in the short-, medium-, and long-run. Our paper presents the first unique empirical evidence in the literature that relates the uncertainty derived from various types of infectious diseases with the predictability of realized volatilities of different international stock market indexes.

\section{Discussion of the Results}

In the context of the literature on forecasting stock market volatility (Poon and Granger 2003), the main contribution of this paper relies on the predictive power of the EMVID variable for international stock markets volatilities. While there is recent literature on the impact of COVID-19 on stock market volatility (Lyócsa and Molnár 2020; Zaremba et al. 2020; Zhang et al. 2020), this paper includes not only the recent COVID-19 outbreak, but other pandemic episodes as well. While past infectious diseases (H1N1 pandemic in 2009-2010, the Ebola outbreak in 2014-2016, the H5N1, MERS or SARV viruses, among others) have not been extensively considered to affect stock market volatilities, this paper shows that the uncertainty related to these infectious diseases can have a significant impact on financial volatility.

Considering that different classes of market participants populate the stock market, where traders in the different classes differ in their sensitivity to information flows at different time horizons (that is, short-term traders versus long-term traders), we analyze the predictability of EMVID at different time horizons. The main results suggest that the predictive power of EMVID is mainly limited to short $(h=1)$ and medium $(h=5)$ horizons, suggesting that this variable seems to have only transitory effects on stock market volatility. This finding is in line with some literature that suggests that the impact of the COVID-19 pandemic on financial markets was lower and less persistent that that observed, for example, after the 2008 Global Financial Crisis (Cunado et al. 2021). 
Finally, it is interesting to analyze the international differences on the forecasting ability of EMVID in different stock markets. It is interesting to note that the most vulnerable stock markets to uncertainty related to infectious diseases are those in Singapore, Portugal and Netherlands. The different responses of international stock market volatilities to EMVID suggest that there are important international portfolio diversification and hedging opportunities in periods of infectious diseases.

\section{Conclusions}

The COVID-19 pandemic questioned the traditional 'safe haven' nature of the international stock market index. Given the heightened uncertainty related to infectious diseases, especially COVID-19, we contribute to the literature by predicting the future path of international stock markets index RV amid daily newspaper-based index uncertainty related to infectious diseases (EMVID). A recursive estimation approach is adopted over the short-, medium-, and long-run using out-of-sample predictability. Our main findings could be summarized as follows. First, they indicate that EMVID plays a critical and significant role in predicting international stock markets index $\mathrm{RV}$, which is in line with the recent literature on the impact of the COVID-19 pandemic on financial volatility, although in this paper we extend our sample period to include uncertainty related to some other infectious diseases. Second, the results suggest that the highest predictive power of EMVID are found for short $(h=1)$ and medium $(h=5)$ horizons, while for the long-run, we find significant predictability power only for the stock markets in Singapore (STI) and Milan (FTMIB). Furthermore, the results suggest that the most vulnerable stock markets to EMVID are those in Singapore (in the short-, medium- and long-run), Portugal and The Netherlands (in the medium- and short-run). When only the COVID-19 episode is considered, the most vulnerable stock markets are those in Portugal and Pakistan.

Assessing the COVID-19 episode, the latter results were evident. These findings have important implications for investors, portfolio managers and policymakers. For example, the results suggest that there are international significant differences in the response of stock markets to infectious diseases, suggesting that international diversification opportunities can be found in the presence of episodes of infectious diseases. Since uncertainty related to infectious diseases will have different sectoral impacts, an analysis of the predictability of EMVID for sectoral stock market volatilities could help exploring sectoral diversification opportunities. Future research will address this issue.

Lastly, our findings highlight the importance of accurate volatility forecast when constructing hedging strategies in the financial market during high uncertainty as a result of pandemics and epidemics. In the future, we will extend our study on the agricultural commodity markets, to analyze the impact of the pandemic on issues of food security associated with price volatility.

Author Contributions: Conceptualization, S.S., J.C. and R.G.; methodology, S.S.; validation, S.S., J.C. and R.G.; formal analysis, S.S., J.C. and R.G.; writing-original draft preparation, S.S., J.C. and R.G.; writing-review and editing, S.S., J.C. and R.G. All authors have read and agreed to the published version of the manuscript.

Funding: Juncal Cunado gratefully acknowledges financial support from Ministerio de Ciencia e Innovación (PID2020-114275GB-I00).

Institutional Review Board Statement: Not applicable.

Informed Consent Statement: Not applicable.

Data Availability Statement: Data are available under request from the authors, but the raw data is publicly available as stated in the data segment.

Conflicts of Interest: The authors declare no conflict of interest. 


\section{Appendix A}

Table A1. Acronyms for each stock market index.

\begin{tabular}{|c|c|c|}
\hline Symbol & Name & City, Country \\
\hline \multicolumn{3}{|c|}{ Europe } \\
\hline 1. AEX & Amsterdam Exchange index & Amsterdam, Netherlands \\
\hline 2. BFX & Bell 20 Index & Brussel, Belgium \\
\hline 3. BVLG & PSI All-Share Index & Lisbon, Portugal \\
\hline 4. FCHI & CAC 40 & Paris, France \\
\hline 5. FTMIB & FTSE MIB & Milan, Italia \\
\hline 6. FTSE & FTSE 100 & London, United Kingdom \\
\hline 7. GDAXI & DAX & Frankfurt, Germany \\
\hline 8. IBEX & IBEX 35 Index & Madrid, Spain \\
\hline 9. OMXC20 & OMX Copenhagen 20 Index & Copenhagen, Denmark \\
\hline 10. OMXHPI & OMX Helsinki All Share Index & Helsinki, France \\
\hline 11. OMXSPI & OMX Stockholm All Share Index & Stockholm, Sweden \\
\hline 12. OSEAX & Oslo Exchange All-share Index & Oslo, Norway \\
\hline 13. SMSI & Madrid General Index & Madrid, Spain \\
\hline 14. SSMI & Swiss Stock Market Index & Zurich, Switzerland \\
\hline 15. STOXX50E & EURO STOXX 50 & Eschborn, Germany \\
\hline \multicolumn{3}{|c|}{ Asia } \\
\hline 16. BSESN & S\&P BSE Sensex & Bombay, India \\
\hline 17. HSI & HANG SENG Index & Hong Kong, China \\
\hline 18. KS11 & Korea Composite Stock Price Index (KOSPI) & Seaul, South Korea \\
\hline 19. KSE & Karachi SE 100 Index & Karachi, Paristan \\
\hline 20. N225 & Nikkei 225 & Tokyo, Japan \\
\hline 21. NSEI & NIFTY 50 & Mumbai, Maharashtra, India \\
\hline 22. SSEC & Shanghai Composite Index & Shanghai, China \\
\hline 23. STI & Straits Times Index & Shenton Way, Singapore \\
\hline \multicolumn{3}{|c|}{ North America } \\
\hline 24. DJI & Dow Jones Industrial Average & New York, United State \\
\hline 25. GSPTSE & S\&P/TSX Composite index & Toronto, Canada \\
\hline 26. IXIC & Nasdaq 100 & New York, United State \\
\hline 27. MXX & IPC Mexico & Mexico City, Mexico \\
\hline 28. RUT & Russel 2000 & New York, United State \\
\hline 29. SPX & S\&P 500 Index & New York, United State \\
\hline \multicolumn{3}{|c|}{ South America } \\
\hline 30. BVSP & BVSP BOVESPA Index & Rio de Janeiro, Brazil \\
\hline \multicolumn{3}{|c|}{ Australia } \\
\hline 31. AORD & All Ordinaries & Sydney, Australia \\
\hline
\end{tabular}

Note: The stock market indexes are grouped by city and country in their respective continents. 

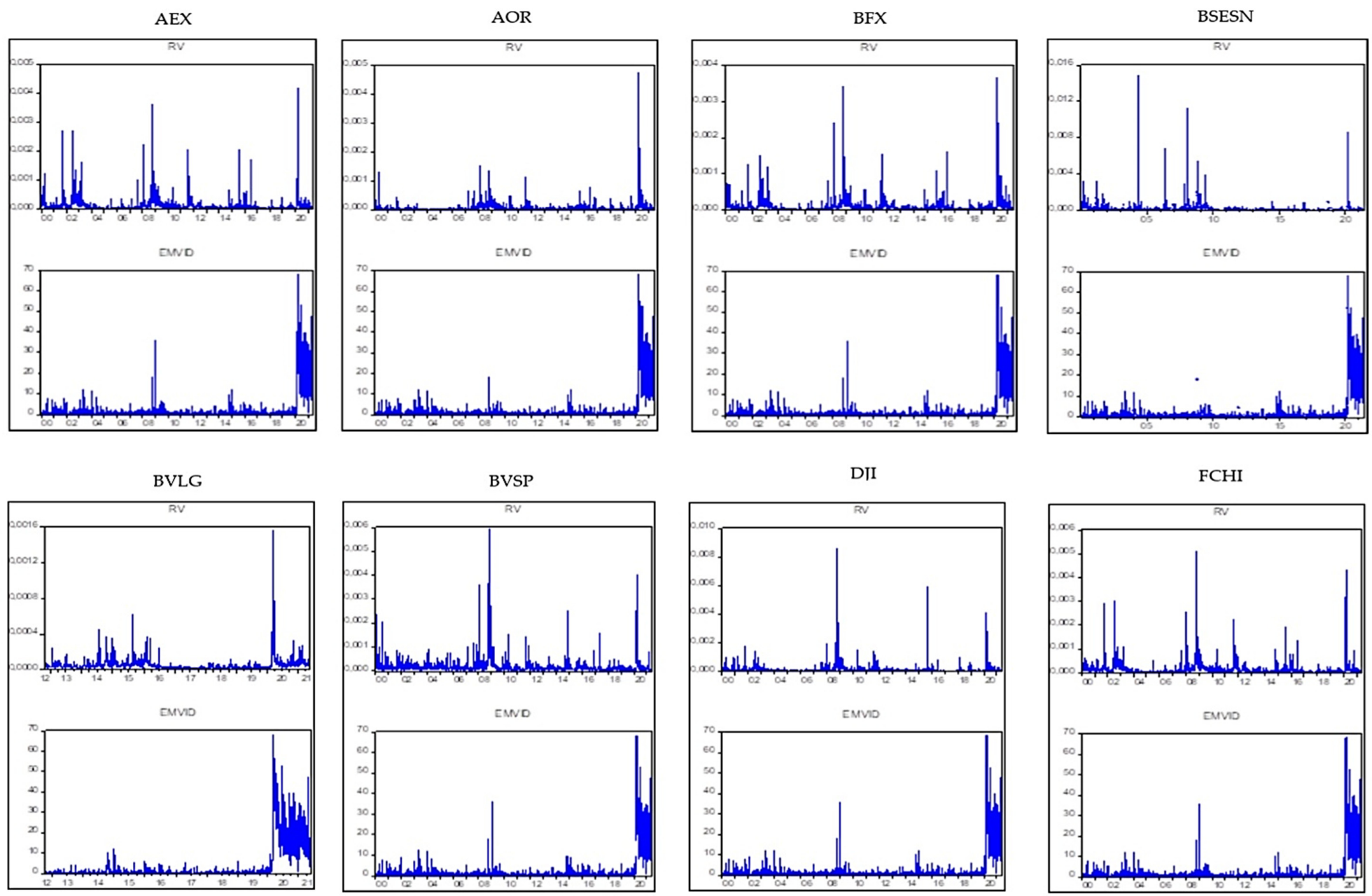

Figure A1. Cont. 

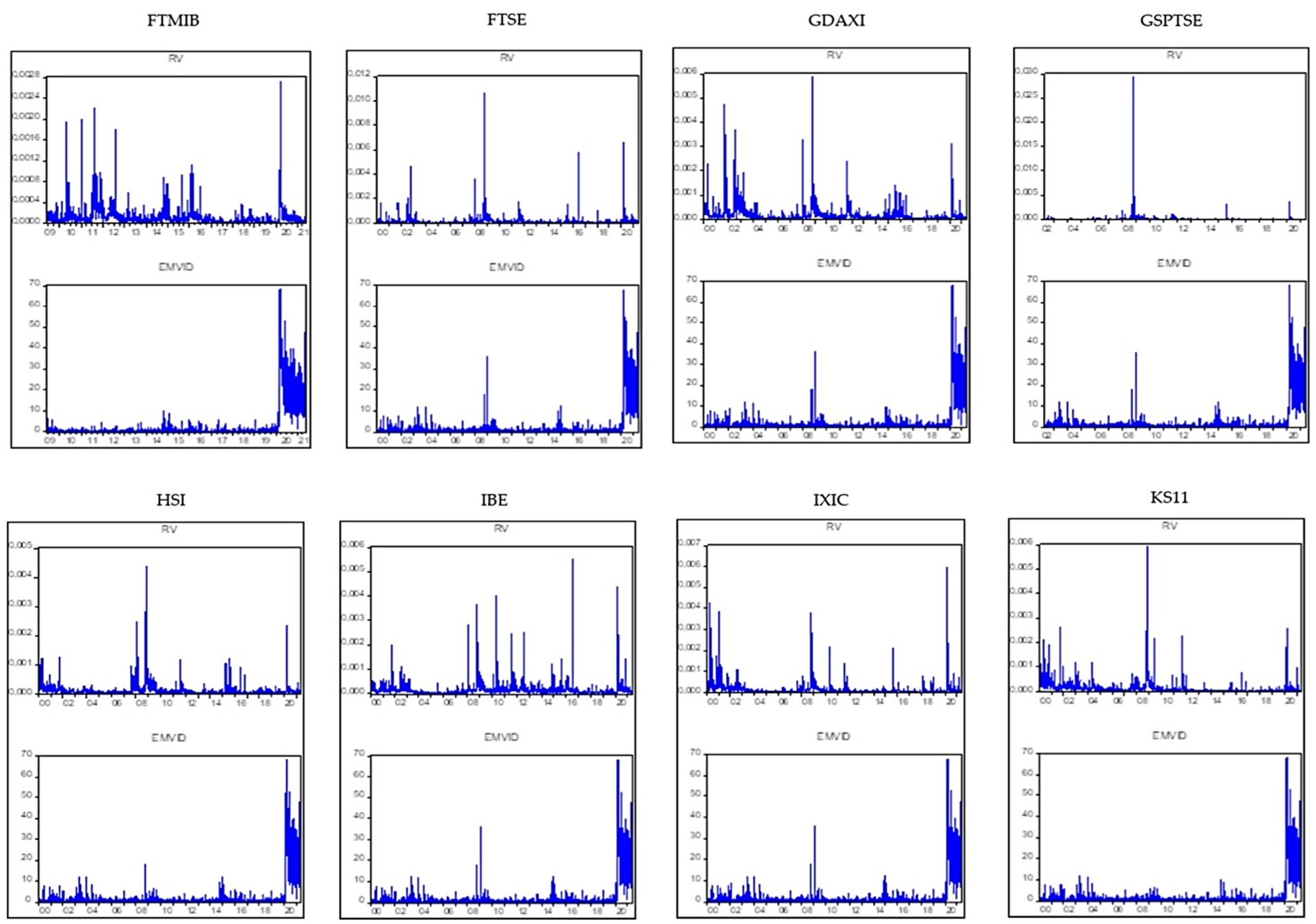

Figure A1. Cont. 

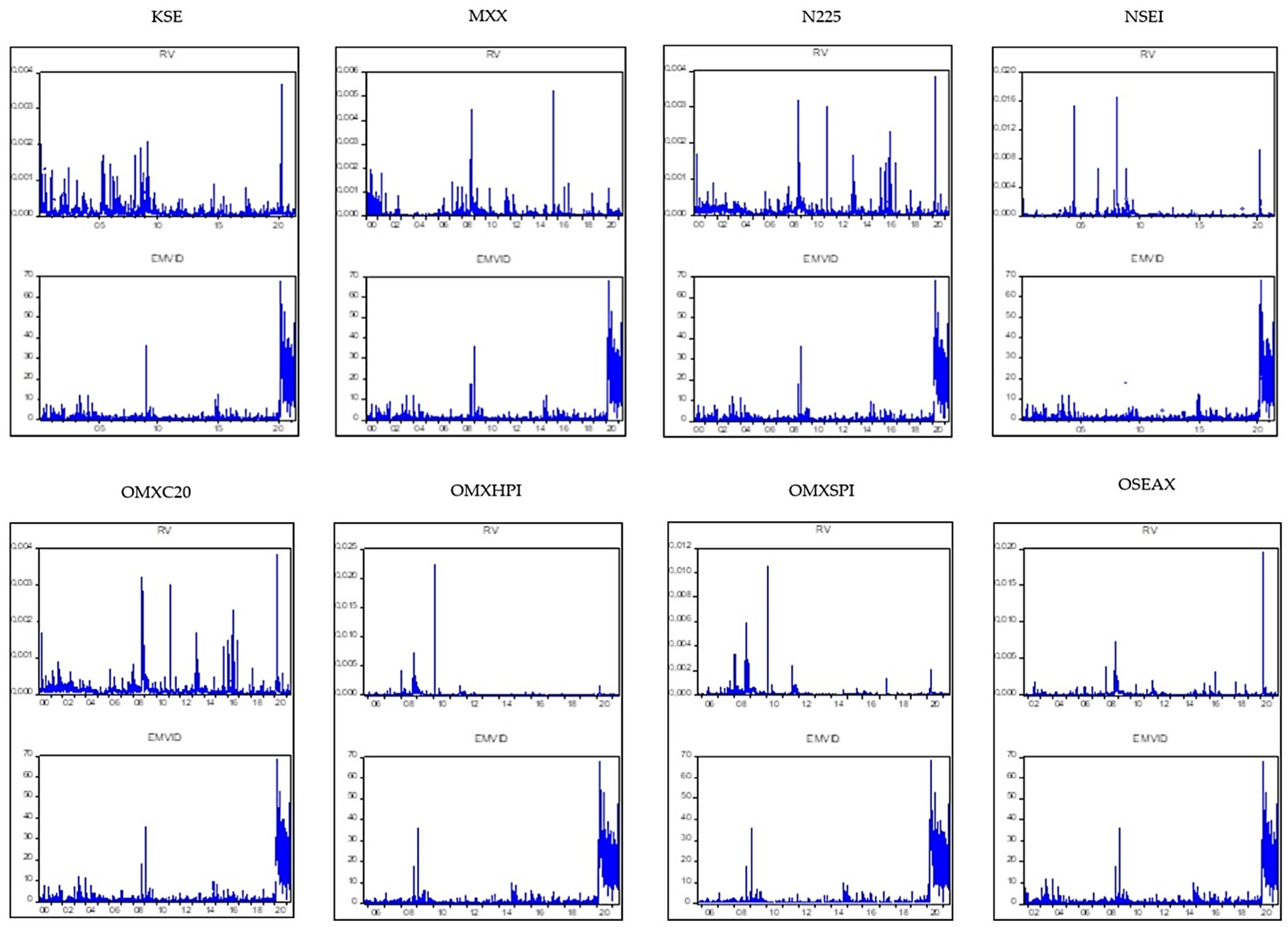

Figure A1. Cont. 

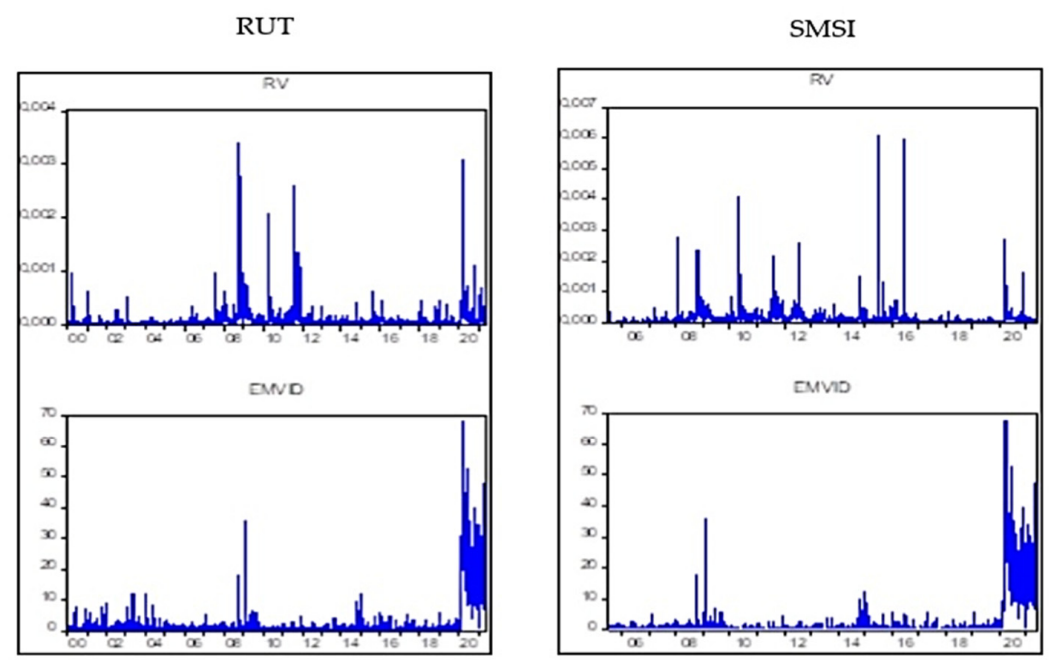

SSMI
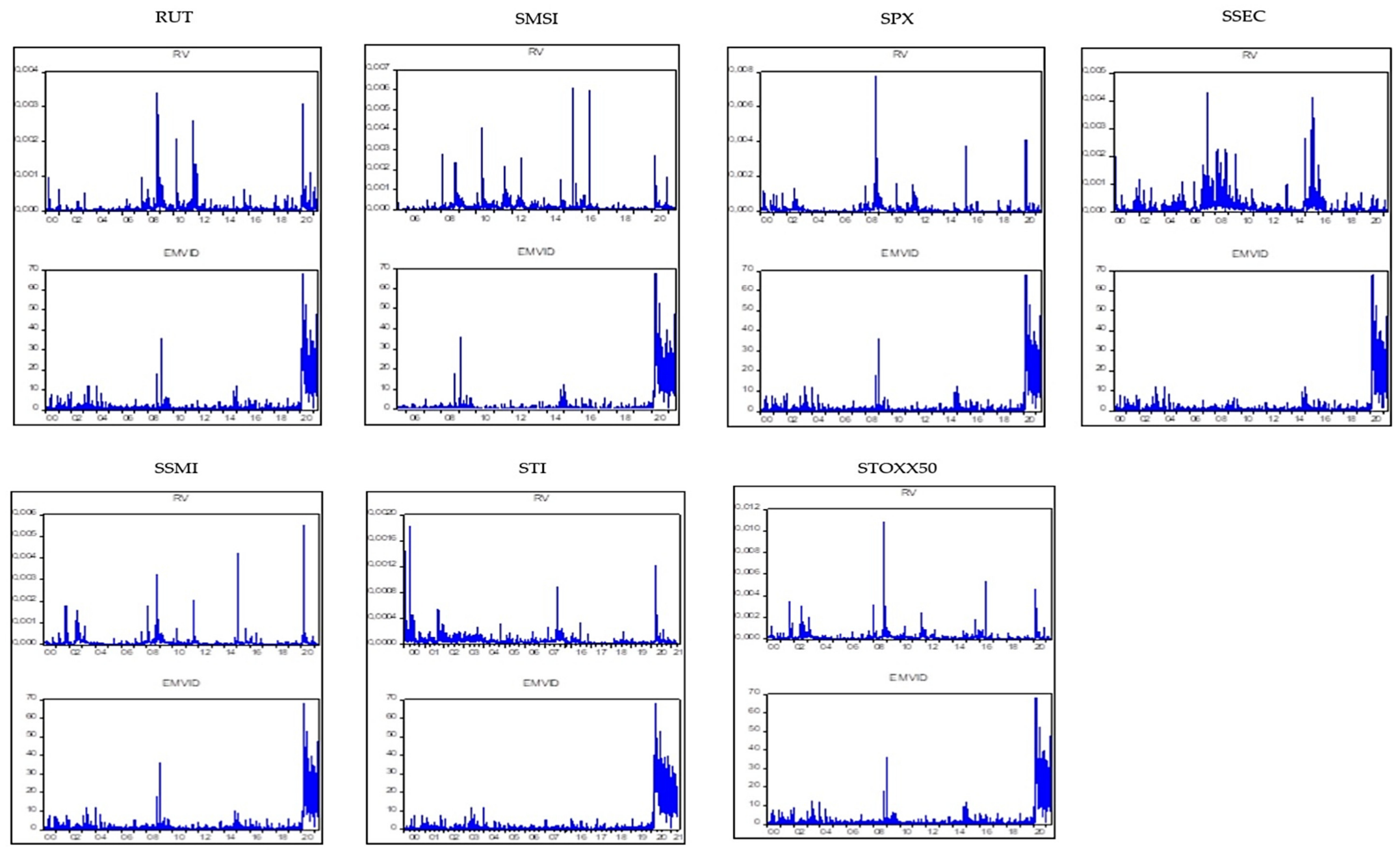

Figure A1. Data Plots. Note: RV is the realized volatility estimates for international stock markets index: EMVID is the newspaper-based uncertainty index due to infectious diseases. * indicates stock markets shocks because of infectious diseases. 
Table A2. Out-of-sample forecasting gains for the COVID-19 episode.

\begin{tabular}{|c|c|c|c|c|c|c|}
\hline $\mathbf{h}$ & RMSE0 & RMSEE 1 & FGs & RMSE0 & RMSEE 1 & FGs \\
\hline \multicolumn{7}{|c|}{ Europe } \\
\hline & \multicolumn{3}{|c|}{ Panel 1: AEX: 3/16/2020 } & \multicolumn{3}{|c|}{ Panel 2: BFX: 3/16/2020 } \\
\hline 1 & 1.9360 & 1.9505 & -0.7438 & 2.1234 & 2.1210 & 0.1135 \\
\hline 5 & 0.6168 & 0.6193 & -0.4034 & 0.5541 & 0.5545 & -0.0853 \\
\hline \multirow[t]{2}{*}{22} & 0.1865 & 0.1867 & -0.0691 & 0.1618 & 0.1615 & 0.2155 \\
\hline & \multicolumn{3}{|c|}{ Panel 3: BVLG: 3/18/2020 } & \multicolumn{3}{|c|}{ Panel 4: FCHI: 3/16/2020 } \\
\hline 1 & 0.6593 & 0.6572 & 0.3162 & 2.4805 & 2.4790 & 0.0597 \\
\hline 5 & 0.1838 & 0.1839 & -0.0625 & 0.6902 & 0.6899 & 0.0406 \\
\hline \multirow[t]{2}{*}{22} & 0.0660 & 0.0654 & 0.9168 & 0.1916 & 0.1913 & 0.1490 \\
\hline & \multicolumn{3}{|c|}{ Panel 5: FTMIB: 3/16/2020 } & \multicolumn{3}{|c|}{ Panel 6: FTSE: 3/16/2020 } \\
\hline 1 & 1.0847 & 1.0839 & 0.0824 & 1.7204 & 1.7216 & -0.0692 \\
\hline 5 & 0.3324 & 0.3326 & -0.0532 & 0.6743 & 0.6712 & 0.4635 \\
\hline \multirow[t]{2}{*}{22} & 2.4875 & 2.4842 & 0.1301 & 0.2173 & 0.2168 & 0.2048 \\
\hline & \multicolumn{3}{|c|}{ Panel 7: GDAX1: 3/16/2020 } & \multicolumn{3}{|c|}{ Panel 8: IBEX: 3/18/2020 } \\
\hline 1 & 1.6569 & 1.6574 & -0.0350 & 1.6970 & 1.6990 & -0.1178 \\
\hline 5 & 0.4315 & 0.4322 & -0.1485 & 0.5262 & 0.5269 & -0.1329 \\
\hline \multirow[t]{2}{*}{22} & 0.1357 & 0.1355 & 0.2045 & 0.1713 & 0.1713 & 0.0012 \\
\hline & \multicolumn{3}{|c|}{ Panel 9: OMXC20: 3/18/2020 } & \multicolumn{3}{|c|}{ Panel 10: OMXHPI: 3/16/2020 } \\
\hline 1 & 1.1987 & 1.1988 & -0.0105 & 0.8285 & 0.8291 & -0.0776 \\
\hline 5 & 0.2935 & 0.2939 & -0.1337 & 0.2196 & 0.2200 & -0.2041 \\
\hline \multirow[t]{2}{*}{22} & 0.1009 & 0.1008 & 0.1478 & 0.0706 & 0.0703 & 0.5281 \\
\hline & \multicolumn{3}{|c|}{ Panel 11: OMXSPI: 3/17/2020 } & \multicolumn{3}{|c|}{ Panel 12: OSEAX: 3/11/2020 } \\
\hline 1 & 0.8960 & 0.8957 & 0.0394 & 2.6408 & 2.7287 & -3.2222 \\
\hline 5 & 0.2071 & 0.2071 & -0.0092 & 2.0396 & 2.0436 & -0.1945 \\
\hline \multirow[t]{2}{*}{22} & 0.0814 & 0.0811 & 0.2996 & 0.5292 & 0.5297 & -0.0831 \\
\hline & \multicolumn{3}{|c|}{ Panel 13: SMSI: 3/16/2020 } & \multicolumn{3}{|c|}{ Panel 14: SSMI: 3/17/2020 } \\
\hline 1 & 1.4601 & 1.4571 & 0.2040 & 1.8434 & 1.8452 & -0.0942 \\
\hline 5 & 0.3939 & 0.3938 & 0.0422 & 0.5770 & 0.5786 & -0.2798 \\
\hline 22 & 0.1312 & 0.1310 & 0.1557 & 0.2138 & 0.2129 & 0.4335 \\
\hline \multicolumn{7}{|c|}{ Panel 15: STOXX50E: 3/16/2020 } \\
\hline 1 & 2.1622 & 2.1663 & -0.1882 & & & \\
\hline 5 & 0.5424 & 0.5441 & -0.3121 & & & \\
\hline 22 & 0.2152 & 0.2141 & 0.5133 & & & \\
\hline & & & Asia & & & \\
\hline & Pane & BSESN: 6 / & /2004 & Par & 17: HIS: $3 / 1$ & 020 \\
\hline 1 & 1.5849 & 1.6314 & -2.8460 & 0.5010 & 0.5184 & -3.3552 \\
\hline 5 & 0.9199 & 0.9189 & 0.1121 & 0.2843 & 0.2839 & 0.1406 \\
\hline 22 & 0.2426 & 0.2427 & -0.0387 & 0.0665 & 0.0668 & -0.4584 \\
\hline & Pan & 8: KS11: 3/ & 2020 & Pan & 9: KSE: $3 / 1$ & 020 \\
\hline 1 & 1.4359 & 1.4280 & 0.5490 & 2.2063 & 2.1875 & 0.8595 \\
\hline 5 & 0.4078 & 0.4017 & 1.5029 & 0.6173 & 0.6116 & 0.9344 \\
\hline 22 & 0.1037 & 0.1035 & 0.1082 & 0.1541 & 0.1539 & 0.1410 \\
\hline & Pane & $0: \mathrm{N} 225: 3 /$ & 2020 & Pan & 1: NSEI: $3 /$ & 2020 \\
\hline 1 & 0.8578 & 0.8597 & -0.2159 & 1.6255 & 1.6764 & -3.0350 \\
\hline 5 & 0.3704 & 0.3722 & -0.4707 & 0.9785 & 0.9769 & 0.1570 \\
\hline 22 & 0.1205 & 0.1207 & -0.1459 & 0.2558 & 0.2564 & -0.2297 \\
\hline
\end{tabular}


Table A2. Cont.

\begin{tabular}{|c|c|c|c|c|c|c|}
\hline h & RMSE0 & RMSEE 1 & FGs & RMSE0 & RMSEE 1 & FGs \\
\hline \multicolumn{7}{|c|}{ Asia } \\
\hline & \multicolumn{3}{|c|}{ Panel 22: SSEC: 3/18/2020 } & \multicolumn{3}{|c|}{ Panel 23: STI: 3/16/2020 } \\
\hline 1 & 0.5192 & 0.5222 & -0.5686 & 0.5072 & 0.5045 & 0.5404 \\
\hline 5 & 0.1389 & 0.1394 & -0.3243 & 0.1697 & 0.1688 & 0.5718 \\
\hline 22 & 0.0400 & 0.0400 & -0.0350 & 0.0456 & 0.0456 & 0.0153 \\
\hline \multicolumn{7}{|c|}{ North America } \\
\hline & \multicolumn{3}{|c|}{ Panel 24: DJI: 3/16/2020 } & \multicolumn{3}{|c|}{ Panel 25: GSPTSE: 3/17/2020 } \\
\hline 1 & 1.8333 & 1.8403 & -0.3792 & 0.6681 & 0.6831 & -2.1965 \\
\hline 5 & 0.4916 & 0.4932 & -0.3256 & 0.3700 & 0.3716 & -0.4322 \\
\hline \multirow[t]{2}{*}{22} & 0.1832 & 0.1826 & 0.3675 & 0.1108 & 0.1105 & 0.3033 \\
\hline & \multicolumn{3}{|c|}{ Panel 26: IXIC: 3/18/2020 } & \multicolumn{3}{|c|}{ Panel 27: MXX: 3/18/2020 } \\
\hline 1 & 1.3779 & 1.3990 & -1.5101 & 0.5697 & 0.5700 & -0.0575 \\
\hline 5 & 0.5258 & 0.5279 & -0.4052 & 0.1697 & 0.1697 & -0.0471 \\
\hline \multirow[t]{2}{*}{22} & 0.1631 & 0.1626 & 0.3014 & 0.0441 & 0.0442 & -0.2601 \\
\hline & \multicolumn{3}{|c|}{ Panel 28: RUT: 3/17/2020 } & \multicolumn{3}{|c|}{ Panel 29: SPX: 3/16/2020 } \\
\hline 1 & 1.8075 & 1.8110 & -0.1880 & 1.8732 & 1.8788 & -0.2985 \\
\hline 5 & 0.5059 & 0.5058 & 0.0263 & 0.5181 & 0.5190 & -0.1746 \\
\hline \multirow[t]{3}{*}{22} & 0.1644 & 0.1627 & $1.0222^{* * *}$ & 0.1824 & 0.1820 & 0.2539 \\
\hline & \multicolumn{3}{|c|}{ South America } & \multicolumn{3}{|c|}{ Australia } \\
\hline & \multicolumn{3}{|c|}{ Panel 30: BVSP: 3/10/2020 } & \multicolumn{3}{|c|}{ Panel 31: AORD: 3/17/2020 } \\
\hline 1 & 2.3643 & 2.3499 & 0.6146 & 2.6429 & 2.6307 & 0.4641 \\
\hline 5 & 0.6400 & 0.6367 & 0.5303 & 0.6724 & 0.6694 & 0.4553 \\
\hline 22 & 0.2010 & 0.2011 & -0.0055 & 0.2126 & 0.2126 & 0.0075 \\
\hline
\end{tabular}

Note: Within the COVID-19 episode, the forecasting gains, $F G=\left(\frac{R M S F E_{0}}{R M S F E_{1}}-1\right) * 100$. where $R M S F E_{0}$ and $R M S F E_{1}$ are root mean squared forecast errors $\left(R M S F E_{s}\right)$ of the benchmark HAR-RV model and the extended HAR-RV model. RV is the daily realised volatility estimation of the international stock market index; EMVID is the newspaper-based uncertainty index due to infectious diseases. ${ }^{* * *}$ indicates significant at a $1 \%$ level.

Table A3. Acronyms of each implied volatility index.

\begin{tabular}{cc}
\hline & EUROPE \\
\hline VSTOXX VOLATILITY INDEX & EU \\
\hline VDAX-NEW VOLATILITY INDEX & GERMANY \\
\hline VSMI VOLATILITY INDEX & SWISS \\
\hline HSI VOLATILITY INDEX & HONG KONG \\
\hline INDIA VOLATILITY INDEX & INDIA \\
\hline VKOSPI VOLATILITY INDEX & KOREA \\
\hline CBOE CHINA ETF VOLATILITY INDEX & CHINA \\
\hline NIKKEI STOCK AVERAGE VOLATILITY INDEX & JAPAN \\
\hline NORTH AMERICA & USA \\
\hline CBOE SPX VOLATILITY VIX (NEW) & CANADA \\
\hline S\&P/TSX COMPOSITE LOW VOLATILITY & AUSTRILIA \\
\hline AUSTRILIA & BRAZIL \\
\hline S\&P/ASX 200 VOLATILITY INDEX & \\
\hline & SOUTH AMERICA \\
\hline SOE BRAZIL ETF VOLATILITY INDEX & AFRICA \\
\hline
\end{tabular}


Table A4. Out-of-sample forecasting gains for the COVID-19 episode.

\begin{tabular}{|c|c|c|c|}
\hline \multicolumn{4}{|c|}{ EUROPE } \\
\hline & RMSE0 & RMSEE 1 & FGs \\
\hline \multicolumn{4}{|c|}{ Panel 1: VSTOXX VOLATILITY INDEX } \\
\hline $\mathrm{h}=1$ & 1.7999 & 1.6686 & 7.8705 \\
\hline $\mathrm{h}=5$ & 0.4366 & 0.4293 & 1.7119 \\
\hline $\mathrm{h}=22$ & 0.1735 & 0.1330 & 30.4683 \\
\hline \multicolumn{4}{|c|}{ Panel 2: VDAX-NEW VOLATILITY INDEX } \\
\hline $\mathrm{h}=1$ & 2.9079 & 2.0593 & 41.2069 \\
\hline $\mathrm{h}=5$ & 0.5717 & 0.5126 & 11.5170 \\
\hline$h=22$ & 0.2712 & 0.2159 & 25.6034 \\
\hline \multicolumn{4}{|c|}{ Panel 3: VSMI VOLATILITY INDEX } \\
\hline $\mathrm{h}=1$ & 2.0768 & 1.6741 & 24.0544 \\
\hline$h=5$ & 0.4200 & 0.4204 & -0.1066 \\
\hline $\mathrm{h}=22$ & 0.2076 & 0.1870 & 11.0462 \\
\hline \multicolumn{4}{|c|}{ ASIA } \\
\hline \multicolumn{4}{|c|}{ Panel 4: HSI VOLATILITY INDEX } \\
\hline $\mathrm{h}=1$ & 1.8673 & 1.8127 & 3.0174 \\
\hline $\mathrm{h}=5$ & 0.4847 & 0.4517 & 7.2982 \\
\hline$h=22$ & 0.1889 & 0.1673 & 12.8981 \\
\hline \multicolumn{4}{|c|}{ Panel 5: INDIA VOLATILITY INDEX } \\
\hline $\mathrm{h}=1$ & 1.5582 & 1.5562 & 0.1331 \\
\hline$h=5$ & 0.4077 & 0.3992 & 2.1224 \\
\hline$h=22$ & 0.1879 & 0.1879 & -0.0218 \\
\hline \multicolumn{4}{|c|}{ Panel 6: VKOSPI VOLATILITY INDEX } \\
\hline $\mathrm{h}=1$ & 2.2884 & 1.8664 & 22.6129 \\
\hline$h=5$ & 0.6329 & 0.4665 & 35.6702 \\
\hline $\mathrm{h}=22$ & 0.1999 & 0.1858 & 7.5766 \\
\hline \multicolumn{4}{|c|}{ Panel 7: CBOE CHINA ETF VOLATILITY INDEX } \\
\hline $\mathrm{h}=1$ & 2.7090 & 2.7104 & -0.0524 \\
\hline$h=5$ & 0.8047 & 0.7594 & 5.9612 \\
\hline$h=22$ & 0.2272 & 0.2105 & 7.9264 \\
\hline \multicolumn{4}{|c|}{ Panel 8: NIKKEI STOCK AVERAGE VOLATILITY INDEX } \\
\hline $\mathrm{h}=1$ & 1.8115 & 1.7283 & 4.8149 \\
\hline$h=5$ & 0.4289 & 0.4025 & 6.5451 \\
\hline $\mathrm{h}=22$ & 0.2105 & 0.1588 & 32.5444 \\
\hline \multicolumn{4}{|c|}{ NORTH AMERICA } \\
\hline \multicolumn{4}{|c|}{ Panel 9: CBOE SPX VOLATILITY VIX (NEW) } \\
\hline $\mathrm{h}=1$ & 2.4810 & 2.4959 & -0.5952 \\
\hline $\mathrm{h}=5$ & 0.6034 & 0.6030 & 0.0721 \\
\hline $\mathrm{h}=22$ & 0.2605 & 0.2270 & 14.7473 \\
\hline \multicolumn{4}{|c|}{ Panel 10: S\&P/TSX COMPOSITE LOW VOLATILITY } \\
\hline $\mathrm{h}=1$ & 4.8002 & 4.6895 & 2.3597 \\
\hline$h=5$ & 1.2127 & 1.1976 & 1.2536 \\
\hline$h=22$ & 0.4849 & 0.4843 & 0.1334 \\
\hline \multicolumn{4}{|c|}{ AUSTRILIA } \\
\hline \multicolumn{4}{|c|}{ Panel 11: S\&P/ASX 200 VOLATILITY INDEX } \\
\hline $\mathrm{h}=1$ & 1.7999 & 1.6686 & 7.8705 \\
\hline$h=5$ & 0.4366 & 0.4293 & 1.7119 \\
\hline$h=22$ & 0.1735 & 0.1330 & 30.4683 \\
\hline
\end{tabular}


Table A4. Cont.

\begin{tabular}{cccc}
\hline \multicolumn{4}{c}{ SOUTH AMERICA } \\
\hline \multicolumn{4}{c}{ Panel 12: CBOE BRAZIL ETF VOLATILITY INDEX } \\
\hline $\mathrm{h}=1$ & 3.3812 & 3.3574 & 0.7070 \\
$\mathrm{~h}=5$ & 0.8698 & 0.8543 & 1.8186 \\
$\mathrm{~h}=22$ & 0.3665 & 0.3673 & -0.2164 \\
\hline \multicolumn{4}{c}{ AFRICA } \\
\hline $\mathrm{h}=1$ & Panel 13: SOUTH AFRICA VOLATILITY INDEX \\
$\mathrm{h}=5$ & 1.1539 & 1.1568 & -0.2519 \\
$\mathrm{~h}=22$ & 0.2886 & 0.2876 & 0.3320 \\
\hline
\end{tabular}

Note: See Notes to Table A2.

\section{Notes}

The critical values at $10 \%, 5 \%$ and $1 \%$ are $3.951,1.548$ and 0.616 .

It is worth noting that at $5 \%$ level of significance several stock markets index in our analysis are statistically significant except for the GDAX1, GSPTSE, HIS, BSESN, OMXHPI, OSEAX, SPX and SSEC.

Also, this is the phase where the vaccination programmes rollout were implemented.

The critical values at $10 \%, 5 \%$ and $1 \%$ are $3.811,1.583$ and 0.693 .

Based on the suggestion of any anonymous referee, we also conducted a similar analysis involving the forecastability of the available implied volatility indices of various countries, as listed in Table A3. As can be seen from the forecasting results reported in Table A4, using the same set-up as in Table A2, COVID-19 related uncertainty tend to produce higher forecasting gains for the implied volatilities of developed rather than emerging equity markets.

\section{References}

Al-Awadhi, Abdullah M., Khaled Alsaifi, Ahmad Al-Awadhi, and Salah Alhammadi. 2020. Death and contagious infectious diseases: Impact of the COVID-19 virus on stock market returns. Journal of Behavioral and Experimental Finance 27: 100326. [CrossRef]

Ashraf, Badar Nadeem. 2021. Stock markets' reaction to COVID-19: Moderating role of national culture. Finance Research Letters 41: 101857. [CrossRef]

Bai, Jushan, and Pierre Perron. 2003. Computation and analysis of multiple structural change models. Journal of Applied Econometrics 18: 1-22. [CrossRef]

Baker, Scott R., Nicholas Bloom, Steven J. Davis, and Stephen J. Terry. 2020a. COVID-Induced Economic Uncertainty; National Bureau of Economic Research No. w26983. Cambridge: National Bureau of Economic Research.

Baker, Scott R., Nicholas Bloom, Steven J. Davis, Kyle J. Kost, Marco C. Sammon, and Tasaneeya Viratyosin. 2020b. The Unprecedented Stock Market Impact of COVID-19; National Bureau of Economic Research No. w26945. Cambridge: National Bureau of Economic Research. [CrossRef]

Boubaker, Heni, Juncal Cunado, Luis A. Gil-Alana, and Rangan Gupta. 2020. Global crises and gold as a safe haven: Evidence from over seven and a half centuries of data. Physica A: Statistical Mechanics and Its Applications 540: 123093. [CrossRef]

Bouri, Elie, Riza Demirer, Rangan Gupta, and Christian Pierdzioch. 2020. Infectious Diseases, Market Uncertainty and Oil Market Volatility. Energies 13: 4090. [CrossRef]

Campbell, John Y. 2008. Estimating the equity premium. Canadian Journal of Economics/Revue Canadienne D'économique 41: 1-21. [CrossRef]

Chen, Yufeng, Wenqi Li, and Fang Qu. 2019. Dynamic asymmetric spillovers and volatility interdependence on China's stock market. Physica A: Statistical Mechanics and Its Applications 523: 825-38. [CrossRef]

Corsi, Fulvio. 2009. A Simple Approximate Long-Memory Model of Realized Volatility. Journal of Financial Econometrics 7: 174-96. [CrossRef]

Cunado, Juncal, David Gabauer, and Rangan Gupta. 2021. Realized Volatility Spillovers between Energy and Metal Markets: A Time-Varying Connectedness Approach. University of Pretoria, Departament of Economics Working Paper Series. Pretoria: University of Pretoria.

Gao, Xue, Yixin Ren, and Muhammad Umar. 2021. To what extent does COVID-19 drive stock market volatility? A comparison between the U.S. and China. Economic Research-Ekonomska Istraživanja, 1-21. [CrossRef]

Gupta, Rangan, Sowmya Subramaniam, Elie Bouri, and Qiang Ji. 2021. Infectious disease-related uncertainty and the safe-haven characteristic of US treasury securities. International Review of Economics \& Finance 71: 289-98. [CrossRef]

Harjoto, Maretno Agus, Fabrizio Rossi, and John K. Paglia. 2021. COVID-19: Stock market reactions to the shock and the stimulus. Applied Economics Letters 28: 795-801. [CrossRef] 
Kang, Sang Hoon, Ron McIver, and Seong-Min Yoon. 2017. Dynamic spillover effects among crude oil, precious metal, and agricultural commodity futures markets. Energy Economics 62: 19-32. [CrossRef]

Khan, Karamat, Huawei Zhao, Han Zhang, Huilin Yang, Muhammad Haroon Shah, and Atif Jahanger. 2020. The Impact of COVID-19 Pandemic on Stock Markets: An Empirical Analysis of World Major Stock Indices. The Journal of Asian Finance, Economics and Business 7: 463-74. [CrossRef]

Kinateder, Harald, Ross Campbell, and Tonmoy Choudhury. 2021. Safe haven in GFC versus COVID-19: 100 turbulent days in the financial markets. Finance Research Letters 43: 101951. [CrossRef]

Kizys, Renatas, Panagiotis Tzouvanas, and Michael Donadelli. 2021. From COVID-19 herd immunity to investor herding in international stock markets: The role of government and regulatory restrictions. International Review of Financial Analysis 74: 101663. [CrossRef]

Kopyl, Kateryna Anatoliyevna, and John Byong-Tek Lee. 2016. How safe are the safe haven assets? Financial Markets and Portfolio Management 30: 453-82. [CrossRef]

Liu, Yuntong, Yu Wei, Qian Wang, and Yi Liu. 2021. International stock market risk contagion during the COVID-19 pandemic. Finance Research Letters, 102145. [CrossRef]

Lyócsa, Štefan, and Peter Molnár. 2020. Stock market oscillations during the corona crash: The role of fear and uncertainty. Finance Research Letters 36: 101707. [CrossRef]

Lyócsa, Štefan, Eduard Baumöhl, Tomáš Výrost, and Peter Molnár. 2020. Fear of the coronavirus and the stock markets. Finance Research Letters 36: 101735. [CrossRef]

Mazur, Mieszko, Man Dang, and Miguel Vega. 2021. COVID-19 and the march 2020 stock market crash. Evidence from S\&P1500. Finance Research Letters 38: 101690. [CrossRef]

McCracken, Michael W. 2007. Asymptotics for out of sample tests of Granger causality. Journal of Econometrics 140: 719-52. [CrossRef]

Müller, Ulrich A., Michel M. Dacorogna, Rakhal D. Davé, Richard B. Olsen, Olivier V. Pictet, and Jacob E. Von Weizsäcker. 1997. Volatilities of different time resolutions-Analyzing the dynamics of market components. Journal of Empirical Finance 4: 213-39. [CrossRef]

Poon, Ser-Huang, and Clive W. J. Granger. 2003. Forecasting volatility in financial markets: A review. Journal of Economic Literature 41: 478-539. [CrossRef]

Shiba, Sisa, and Rangan Gupta. 2021. Uncertainty related to infectious diseases and forecastability of the realized volatility of us treasury securities. Annals of Financial Economics 16: 2150008. [CrossRef]

Wang, Xinya, Huifang Liu, Shupei Huang, and Brian Lucey. 2019. Identifying the multiscale financial contagion in precious metal markets. International Review of Financial Analysis 63: 209-19. [CrossRef]

Wang, Jiqian, Xinjie Lu, Feng He, and Feng Ma. 2020. Which popular predictor is more useful to forecast international stock markets during the coronavirus pandemic: VIX vs. EPU? International Review of Financial Analysis 72: 101596. [CrossRef]

Zaremba, Adam, Renatas Kizys, David Y. Aharon, and Ender Demir. 2020. Infected Markets: Novel Coronavirus, Government Interventions, and Stock Return Volatility around the Globe. Finance Research Letters 35: 101597. [CrossRef]

Zaremba, Adam, Renatas Kizys, Panagiotis Tzouvanas, David Y. Aharon, and Ender Demir. 2021. The quest for multidimensional financial immunity to the COVID-19 pandemic: Evidence from international stock markets. Journal of International Financial Markets, Institutions and Money 71: 101284. [CrossRef]

Zhang, Yue-Jun, and Yi-Ming Wei. 2010. The crude oil market and the gold market: Evidence for cointegration, causality and price discovery. Resources Policy 35: 168-77. [CrossRef]

Zhang, Dayong, Min Hu, and Qiang Ji. 2020. Financial markets under the global pandemic of COVID-19. Finance Research Letters 36: 101528. [CrossRef] [PubMed]

Zhang, Ning, Aiqun Wang, Naveed-Ul Haq, and Safia Nosheen. 2021. The impact of COVID-19 shocks on the volatility of stock markets in technologically advanced countries. Economic Research-Ekonomska Istraživanja, 1-26. [CrossRef] 